DOI:

\title{
TOPICAL ISSUES OF TEACHING TO READ IN RUSSIAN \\ IN GEORGIAN UNIVERSITIES
}

\author{
Aleksidze Marine \\ Doctor of Philological Science \\ Associate Professor of the Institute of Slavistics \\ Ivane Javakhishvili Tbilisi State University \\ Guruli Laura \\ Lecturer of the Language Center \\ Tbilisi Ivane Javakhishvili State University \\ (Tbilisi, Georgia) \\ e-mail: malexidze@yahoo.com \\ lguruli@mail.ru
}

\begin{abstract}
The methodology of foreign language teaching in higher education keeps paying particular attention to reading in foreign languages. The development of reading in a foreign language, as one of the four main types of speech activity, which is part of speech competency, helps achieve one of the key aims of foreign language teaching - formation of foreign language communicative competency in all diversity of its components. Reading is one of the primary types of activity among students in higher education, as reading helps develop reading skills, shape mixed language and speech skills, transform learner's knowledge in frames of all learned disciplines. For a future professional, reading in a foreign language is not only a means to satisfy his or her cultural requirements, but in the first place, is a means to master their future profession, a means to satisfy their professional interests. Due to this, it is important to organize the process of teaching of foreign languages so that it responds to contemporary requirements of teaching and to social demands. The presentation discusses the questions of teaching reading to undergraduate students on the basis of the handbook created by the authors 'We Read and Write in Russian' (Tbilisi, 2016) and it also suggests several directions towards the optimization of this process.
\end{abstract}

Keywords: reading, speech activity, text in a foreign language, information

\section{АКТУАЛЬНЫЕ ВОПРОСЫ ОБУЧЕНИЯ ЧТЕНИЮ НА РУССКОМ ЯЗЫКЕ СТУДЕНТОВ ВУЗОВ ГРУЗИИ}

\author{
Алексидзе Марина \\ Доктор филологических наук \\ Ассоциированный профессор Института славистики факультета гуманитарных наук \\ Тбилисский государственный университет \\ им. Иванэ Джавахишвили \\ (Тбилиси, Грузия) \\ e-mail: malexidze@yahoo.com \\ Гурули Лаура \\ Преподаватель языкового центра \\ Тбилисский государственный университет \\ им. Иванэ Джавахишвили \\ (Тбилиси, Грузия) \\ lguruli@mail.ru
}

\begin{abstract}
Аннотация. Методика обучения иностранным языкам в вузе по-прежнему уделяет большое внимание обучению чтению на иностранном языке. Развитие умений чтения на иностранном языке, как одного из четырех основных видов речевой деятельности, входящих в состав речевой компетенции способствует достижению одной из ключевых целей обучения иностранным языкам - сформированности иноязычной коммуникативной компетенции во всем многообразии ее компонентов. Чтение является одним из ведущих видов деятельности студентов на этапе обучения в вузе, т.к. обучение чтению позволяет формировать навыки и умения чтения, формировать смежные языковые и речевые умения, трансформировать знания обучающегося в рамках всех изучаемых дисциплин. Для будущего профессионала чтение на иностранном языке выступает не только как средство удовлетворения его культурных потребностей, но в первую очередь как средство овладения будущей профессией, средство удовлетворения его профессиональных интересов. В связи с этим важно организовать процесс обучения иноязычному чтению таким образом, чтобы он отвечал современным целям обучения и социальному заказу общества. В статье рассматриваются вопросы обучения чтению студентов-бакалавров на материале созданного авторами учебного пособия «Читаем и говорим по-русски» (Тбилиси, 2016) и намечаются возможные пути оптимизации этого процесса.
\end{abstract}

Ключевые слова: чтение, речевая деятельность, чтение на иностранном языке, информация

ВВЕДЕНИЕ. В настоящее время чтение является одним из важнейших иноязычных умений, которыми должен овладеть бакалавр в процессе обучения иностранным языкам. Для будущего профессионала чтение на иностранном языке выступает не только как средство удовлетворения его культурных потребностей, но в 
первую очередь как средство овладения будущей профессией, средство удовлетворения его профессиональных интересов. В связи с этим важно организовать процесс обучения иноязычному чтению таким образом, чтобы он отвечал современным целям обучения и социальному заказу общества. Развитие умений чтения на иностранном языке, как одного из четырех основных видов речевой деятельности, входящих в состав речевой компетенции, способствует достижению одной из ключевых целей обучения иностранным языкам - сформированности иноязычной коммуникативной компетенции во всем многообразии ее компонентов.

ОБЗОР ЛИТЕРАТУРЫ. Обучению чтению на иностранном языке уделяет большое внимание российская методика обучения иностранным языкам. Проблема обучения чтению всегда находилась под пристальным вниманием ученых-методистов, начиная с XIX века. Она получила осмысление в трудах Ф.И. Буслаева, В.И. Водовозова, В.В. Данилова, В.П. Острогорского, Ј.В. Поливанова, М.А. Рыбниковой, Н.М. Соколова. Во второй половине XX века организация чтения была выделена как отдельная научная проблема в монографиях Е.В. Крятковского, Н.Д. Молдавской, Н.Н. Светловской, продолжалось рассмотрение чтения в контексте проблем педагогике, методики в работах О.Ю. Богдановой, М.Г. Качурина, Н.И. Кудряшевой и др. Анализ большого количества работ в этой области показывает, что для российской методической науки характерна последовательная, систематическая и глубокая разработка актуальных вопросов обучения такому виду речевой деятельности как чтение (Obuchenie chteniu ..., 2016).

МЕТОДЫ ИССЛЕДОВАНИЯ. В работе был использован описательно-аналитический метод как для анализа специальной литературы по теме исследования, так и для описания принципов работы по составленному авторами учебнику «Читаем и говорим по-русски» (Тбилиси 2016).

РЕЗУЛЬТАТЫ И ДИСКУССИЯ. Чтение представляет собой вид коммуникативной деятельности, под которой понимается такая специфическая форма взаимодействия человека с другими людьми в процессе общения, которая опосредуется языком.

Требование учета принципа коммуникативности при обучении русскому языку как иностранному обусловливает практическую направленность обучения, функциональный подход к отбору и презентации языкового материала, ситуативно-тематическое его представление, а также выделение определенных этапов обучения (Kostomarov and Mitrofanova 1988).

Надо отметить, что в некоторых современных лингвометодических работах, посвященных проблемам преподавания РКИ, обнаруживается дифференцированный подход к описанию языковой системы то на основе активной грамматики, то на основе пассивной - в зависимости от целей обучения: « активная грамматика обеспечивает учащимся общение в рамках учебно-бытовых ситуаций и включает поэтому в качестве основных аспектов речевой деятельности слушание, говорение и письмо, а в качестве дополнительного аспекта - чтение; пассивная грамматика ... включает в качестве основного аспекта речевой деятельности чтение...» (Rozhkova 1978).

В процессе общения человек имеет дело с речью. Речь является способом формирования и формулирования мысли, заложенной в текст. Читающий стоит перед задачей овладеть этим способом, т.е. речью.

Каковы особенности чтения как коммуникативной деятельности, если она проходит на иностранном языке? Из психологии обучения иностранным языкам известно, что структура и психологическое содержание деятельности не зависят от того, на каком языке она осуществляется - на родном или иностранном. Коммуникативная деятельность как на родном, так и на иностранном языке относится к одному и тому же классу речемыслительных процессов. Обучение чтению на иностранном языке - это прежде всего обучение иноязычной речи в процессе речевой деятельности. Такой подход при обучении чтению на иностранном языке представляет принципиально важный момент методической концепции обучения чтению (Pholomkina 1974; Mirolubov 2010) При таком подходе целесообразной становится только такая учебная деятельность, которая основывается на знании ее закономерностей и составляющих ее действий. Основной становится обучение иноязычной речи в процессе чтения.

Методика обучению взрослых учащихся - студентов, у которых уже сформирована коммуникативная деятельность на родном языке, имеет ту особенность, что они могут принимать информацию при чтении на родном языке, у них уже есть запас сформированных речевых умений и навыков. Это обстоятельство оказывается важным позитивным фактором при моделировании системы обучения чтению. У многих студентов навыки приема информации уже существуют на первом иностранном языке. Таким образом, психологической основой для становления деятельности на иностранном языке являются сформированные ранее речевые навыки и умения, и это является важным принципом методической системы, предназначенной для обучения взрослых (Gapochka 1978).

На становление иноязычного речевого процесса оказывают влияние и индивидуальные особенности учащихся - особенности внимания, памяти, наблюдательность, способности догадки, прогнозирования, логическое мышление (Akishina and Kagan 2002). Немаловажную роль играют также некоторые умения и навыки интеллектуального порядка. В процессе овладения интеллектуальными функциями решающую роль играет обучение вообще, в том числе и обучение иностранному языку. Важная роль в развитии и продвижении этих функций принадлежит чтению - на родном и иностранных языках. Следовательно, вторым принципом обучения чтению является принцип направленности на развитие мыслительных операций (Gapochka 1978).

Цель обучения чтению - раскрытие смысловых связей (понимание) речевого произведения, представленного в письменном виде. Для того чтобы научиться читать, необходимо выработать определенные навыки и умения. Их условно делят на две группы: 
1)навыки и умения, обеспечивающие техническую сторону (восприятие графических знаков, соотношение их с определенным значением);

2)навыки и умения, позволяющие воспринять смысл текста (установление смысловых связей в тексте, восприятие его содержания).

Можно различить два уровня понимания текста: уровень значения (получение информации) и уровень смысла (понимание замысла автора, оценка и отношение к нему читающего) (Akishina and Kagan 2002).

Понимание и переработка смысловой информации при чтении - сложнейший внутренний процесс, который зависит от определенных мыслительных функций, от уровня языковых знаний, от уровня развитости навыков и умений читать на иностранном языке, от характера текста и его трудностей (Gapochka 1978). Мыслительная деятельность взрослых учащихся является ведущим звеном при овладении навыками и умениями иноязычного чтения. Уровень ее составляет тот фон, который убыстряет или замедляет процесс формирования нужных навыков чтения на иностранном языке (Protasova 1983; Likhacheva 2015)

Обучение чтению на иностранном языке строится обычно от элементов к целому, т.е. считается, что, если учащийся усвоит отдельные буквы, научится сочетать их друг с другом, начнет узнавать их в тексте, он научится читать. По мнению современных методистов, это не так. Нельзя считать, что учащиеся смогут читать, не освоив такие мыслительные операции, как умение соотносить внешний образ слова с его внутренним содержанием, прогнозировать, предвидеть следующие слова, фразы, отбирать нужную информацию (Аkishina and Kagan 2002).

Механизмы чтения формируются дифференцированно, под воздействием определенных методов обучения. Для каждой стадии их формирования необходимо определить рациональные методические действия, их последовательность и системность, а также учебный текстовой материал. Текст определяет характер и целесообразность тех или иных речевых и мыслительных действий для извлечения из него информации и ее смысловой переработки.

Текст имеет и определенное психологическое воздействие на учащегося. Текст для чтения должен рассматриваться как объект, на который направлена коммуникативная деятельность учащихся. Если чтение это цель обучения, то тексты являются средством для реализации этой цели. При отборе и классификации текстов для целей обучения чтению основным принципом должен стать принцип методической предназначенности текста. (Gapochka 1978)

При построении методической программы необходимо на каждом этапе учебного чтения определить, какие виды чтения являются целью обучения. Выбор видов чтения и соотнесение их с типами текстов обусловлены учебно-профессиональными целями учащихся, изучающих иностранный язык. Основной вид чтения, которым пользуются студенты, обучающиеся иностранным языкам на всех этапах обучения, особенно на начальном этапе - это изучающее чтение.

Таким образом, при построении системы обучения иноязычному чтению необходимо принимать во внимание принципы разного порядка - лингвистического, коммуникативного, психологического, которые должны представлять систему, позволяющую найти оптимальные пути и способы формирования рассматриваемого вида речевой деятельности.

Все вышесказанное надо по возможности учитывать при составлении учебного пособия по чтению и говорению, недостаток которых явно ощущается при обучении русскому языку в высших учебных заведениях, в частности в Тбилисском государственном университете им. И. Джавахишвили.

Надо отметить, что в связи с рядом факторов, а именно, с расширением влияния российского капитала, с развитием туризма и т. п., в наши дни в Грузии возрастают потребности в практическом владении русским языком и, как следствие, выдвигается практическая цель обучения русскому языку.

В последние годы политика государства направлена на расширение межнациональных связей и вовлечение людей разной национальности, живущих в сельских регионах Грузии, в культурную и общественную жизнь страны. В связи с этим, в вузах Грузии, в частности в Тбилисском государственном университете имени И. Джавахишвили, получили широкое распространение группы, где наряду с грузинами обучаются студенты армянской и азербайджанской национальности из отдаленных районов Грузии, поступающие в вуз по специальной государственной программе. Они изучают грузинский язык на подготовительном факультете университета, а затем продолжают учебу в вузе на грузинском языке, не всегда в совершенстве владея им. При это общая подготовка таких студентов также оставляет желать лучшего. В связи с этим надо учитывать трудности, которые возникают в аудитории, когда для части студентов, сидящих в одной аудитории, иностранный язык (в данном случае русский) является вторым после первого, каковым является грузинский язык для лиц негрузинской национальности, а для части (имеются в виду студенты-грузины) русский язык является первым иностранным языком (за исключением западноевропейских факультетов). В среднем на изучение русского языка выделено 4 часа в неделю, что ставит перед преподавателем нелегкую задачу распределения этих часов на обучение чтению, аудированию, говорению и письму.

Учитывая рассмотренные выше принципы обучения чтению, авторы разработали учебное пособие «Читаем и говорим по-русски» для студентов, изучающих русский язык на базе грузинского языка, который для определенной части учащихся, как было отмечено выше, является вторым иностранным языком. Кроме того, не всегда удается выделить группы с одинаковым уровнем владения русским языком, вследствие чего в учебное пособие были включены и тексты, рассчитанные на более подготовленных в языковом отношении учащихся. Часть этих текстов предназначена для самостоятельного внеклассного прочитывания, т. е. для домашнего чтения, которое помогает студентам, в достаточной степени владеющим русским языком, совершенствовать 
навыки догадки и прогнозирования текста и способствует дальнейшему развитию словарного запаса и их интеллектуальных способностей. Для них же, в основном, предназначена рубрика «Знаете ли Вы? ...», которая дается после текста и тематически связана с содержанием каждого из них. Поскольку эта рубрика требует уже сформированных навыков чтения, то ее содержание в группе пересказывают после прочтения студенты, владеющие русским языком лучше, чем другие. Информация живо обсуждается среди студентов, развивая у них навыки слушания и говорения.

В данное учебное издание включены сюжетные тексты - оригинальные тексты, адаптированные, как правило, путем сокращения и компиляции в интересах реализации задач обучения. В основном они предлагаются впервые и не представлены (за редким исключением) в других изданиях по русскому языку как иностранному. Тексты располагаются по степени нарастающей сложности, что позволяет преподавателю выбрать необходимый материал, ориентируясь на уровень подготовки студенческой группы.

В первом семестре ведется работа по формированию умений и навыков только в изучающем чтении, которое сопровождается выписками новых слов и словосочетаний. На этом этапе необходима строгая минимизация лексики. Студентам предлагаются небольшие сказки: «Белка и Волк», «Бедняк и богач», «Сорока и ее дети» и т. д. Все они носят в себе устоявшиеся в обществе моральные принципы, которые в наше время для некоторой части молодежи становятся неприемлемыми в связи с ухудшением жизненных условий. Такого рода небольшие тексты живо обсуждаются в аудитории, в конце каждого текста студентам предлагается написать небольшое эссе по обсуждаемой теме. Такой живой интерес к тексту дает возможность преподавателю вовлечь всех студентов в обсуждение темы и помогает им выполнить упражнения на запоминание, выработку языковой и смысловой догадки. Основная цель преподавателя - развить в студентах навыки прогнозирования, догадки, способствовать накоплению лексико-грамматического материала.

Все тексты снабжены ударениями и переводом на грузинский язык большого количества новых для учащихся слов, данных на полях, что способствует снятию трудностей при чтении из-за непонимания содержания текста.

Необходимой составной частью курса по чтению является система лексических и лексико-грамматических упражнений. В пособии представлены такие типы упражнений, как например: найдите правильное завершение предложения; соедините две части высказывания; выберите правильные ответы на вопросы; подтвердите или опровергните данную в предложениях информацию; замените прямую речь косвенной; вставьте глаголы в правильной форме и под.

Основная цель предлагаемых в нашем учебнике послетекстовых упражнений - закрепить новые знания в отношении лексики и помочь студентам удержать в памяти новые слова, после того как они уже поработали с текстом. Уже сам факт, что студенты вновь встретятся с этими словами, может стать решающим для их запоминания.

С помощью послетекстовых заданий проверяется понимание прочитанного, варьируется смысловая обработка информации текста, расширяется словарный запас обучаемых, активизируется их устная речь и обогащаются фоновые знания. Кроме того, послетекстовые задания нацелены на выработку умений ориентироваться в языковой системе. Как правило, после выполнения этих заданий студенты за одно задание осваивают предлагаемый им текст, что повышает мотивацию учащихся.

Все упражнения направлены на развитие не только навыков чтения, но и аудирования, говорения, и письма, что при ограниченном количестве выделяемых на изучение иностранных языков часов является немаловажным условием для работы в студенческой аудитории.

В конце каждого раздела осуществляется обобщение, повторение и своего рода контроль степени усвоения учащимися пройденного материала. Такой подход важен и для преподавателя: он помогает вносить необходимую коррекцию в дальнейший курс РКИ по результатам таких обобщений и проверок.

Как известно, сторонники коммуникативного метода советуют избегать прямого перевода на родной язык учащихся. В нашем учебном пособии мы даем задания на перевод отдельных предложений или целых отрывков из текста с грузинского языка на русский и с русского на грузинский в качестве эффективного контроля сформированности лексико-грамматических навыков. Родной язык учащихся используется нами также в качестве средства схематизации иностранных слов. Использование родного языка в целом должно носить осознанный и целенаправленный характер и быть ограничено определенным количеством ситуаций, где он не только не мешает, но и способствует оптимизации учебного процесса. Классическими в этом плане, как, впрочем, и по многим другим проблемам, считаются работы Л. В. Щербы, который считал, что можно изгнать родной язык учащихся из учебников, но его нельзя изгнать из голов учащихся. Он писал: «Мы должны признать раз и навсегда, что родной язык учащихся участвует в наших уроках иностранного языка, как бы мы ни хотели его изгнать. И мы должны из врага превратить его в друга». (Scherba 1974)

ЗАКЛЮЧЕНИЕ. Таким образом, практика показала, что использование принципа коммуникативности, положенного в основу нашего учебника, дает положительные результаты. С первых уроков учащиеся начинают говорить, наращивая навыки чтения и речевые навыки. Система уроков учебника и их содержание способствуют постоянному пополнению словаря студентов, усвоению необходимого объёма русской грамматики, обеспечивают формирование устойчивых навыков общения в обиходно-бытовой, социальнокультурной, общественно-политической сферах. 


\title{
LIST OF REFERENCES
}

Akishina, A. A., Kagan, O.E. (2002). Uchimsya uchit [Learning to learn]. Moskva: Russkij yazyk.

Gapochka, I. K. (1978). O sistemnosti metodiki obucheniya chteniyu [About systematic methods of teaching reading]. In the:

Prepodavanye russkogo yazyka studentam i spetsialistam nephilologicheskogo prophilya. Moskva: Russkij yazyk.

Kostomarov, V. G., Mitrophanova, O.D. (1988). Metodicheskoye rukovodstvo dlya prepodavatelej russkogo jazyka inostrantsam

[Methodological guide for Russian language teachers to foreigners]. Moskva: Russkij yazyk.

Likhacheva, O.N. (2015). Osobennostyobucheniachteniustudentovnejazykovyxvuzov [Features of teaching reading to students of non-linguistic universities].Nauchnye Trudy Kubanskogouniversiteta, (12), $50-62$.

Mirolubov, A.A. (2010). Metodikaobucheniainostrannymjazykam. [Methods of teaching foreign languages].Moskva: Prosveshchenie Obucheniechteniu... (2016). Obucheniechteniunainostrannomjazyke v sovremennomuniversitete: teoriaipraktika:

monographia[Teaching reading in a foreign language at a modern University: theory and practice: monograph. / Edited by Bagramova N. V., Smirnova N. V., ShemelevaI.Yu.]Saint-Petersburg: Zlatoust.

Protasova, T. N. (1983). Uchet individualnykh osobennostej studentov-inostrantsev pri obuchenii chteniyu na russkom jazyke (nachalnyi etap) [Consideration of the individual characteristics of foreign students in teaching reading in Russian (the first stage)]. Moskva: Russkij yazyk.

Rozhkova, G. I. (1978). Voprosy prakticheskoj grammatiki v prepodavanii russkogo jazyka kak inostrannogo [Questions of practical grammar in teaching Russian as a foreign language]. Moskva: Russkij yazyk.

Pholomkina, S. K. (1974). Printsipy obucheniya chteniyu na inostrannom jazyke [Principles of learning to read in a foreign language]. In the: Metodika prepodavaniya inostrannykh yazykov v vuze. Moskva: Russkij yazyk.

Scherba, L.V. (1974). Yazykovaya systema i rechevaya deyatelnost [Language system and speech activity. Leningrad: Nauka.

\section{For citation:}

Aleksidze Marine, Guruli Laura (2019) TOPICAL ISSUES OF TEACHING TO READ IN RUSSIAN IN GEORGIAN UNIVERSITIES // International Scientific-Pedagogical Organization of Philologists “ WEST-EAST ” (ISPOP). Scientific Journal WEST-EAST. Vol 2/1 N1 (October, 2019). pp. 115-119. doi:

\section{Для цитирования:}

Алексидзе Марина. Гурули Лаура (2019) АКТУАЛЬНЫЕ ВОПРОСЫ ОБУЧЕНИЯ ЧТЕНИЮ НА РУССКОМ ЯЗЫКЕ СТУДЕНТОВ ВУЗОВ ГРУЗИИ // Internationa 1Scientific-Pedagogical Organization of Philologists “ WEST-EAST ” (ISPOP) . Scientific Journal WEST-EAST. Vol 1/1 N1 (October, 2019). C. 115-119. doi:

Information about the author: Marine Aleksidze - associate Professor of the Institute of Slavistics,

Ivane Javakhishvili Tbilisi State University, Georgia, Tbilisi

e-mail: malexidze@yahoo.com

Сведения об авторе: Алексидзе Марина Джондоевна - ассоциированный профессор Института славистики факультета гуманитарных наук Тбилисского государственного, университета им. Иванэ Джавахишвили, Тбилиси, Грузия.

e-mail: malexidze@yahoo.com

Information about the author: Laura Guruli - lecturer of the language center, Ivane Javakhishvili Tbilisi State University, Georgia, Tbilisi e-mail: lguruli@mail.ru

Сведения об авторе: Гурули Лаура Михайловна - преподаватель языкового центра Тбилисского государственного университета им. Иванэ Джавахишвили, Тбилиси, Грузия.

e-mail: lguruli@mail.ru

DOI:

\section{LANGUAGES AND INTERMEDIATE LANGUAGE - POLYFONY AS A METHOD OF TEACHING LEXIS AND ITS RESEARCH}

\author{
Archan Sarkar \\ Doctor in Russian, Rtd. Professor \\ Dept. of Languages, Calcutta university \\ (Calcutta, India) \\ e-mail : archansirkar@yahoo.co.in
}

\begin{abstract}
The present article aims to illustrate a methodological solution of teaching the lexical aspect of Russian as a foreign language. It takes into consideration the experience of teaching Russian in Bengali auditoriums where English happens to be an intermediate language and explores the theoretical grounds of lexical semantics, considered as an important area for a comparative study of lexical systems of languages. The given work reveals that the uniqueness of the lexical system of a language lies in the semantic structure of individual words. Foreigners' problems of mastering a lexis and its system, arising out of the abovementioned phenomenon are identified in this study and methodological recommendations are suggested considering informations of similar as well as dissimilar nature chiefly pertaining to semantic structure of words and their equivalents from the native language of the learners, the target language and the language-mediator.
\end{abstract}

Key words: learner's semantization, desemantization, lexical semantics, LSV 